\title{
Effect of Spirulina maxima Supplementation on Calcium, Magnesium, Iron, and Zinc Status in Obese Patients with Treated Hypertension
}

\author{
J. Suliburska ${ }^{1}$ - M. Szulińska ${ }^{2}$ A. A. Tinkov ${ }^{3,4} \cdot$ P. Bogdański $^{2}$
}

Received: 25 October 2015 / Accepted: 7 January 2016 / Published online: 16 January 2016

(C) The Author(s) 2016. This article is published with open access at Springerlink.com

\begin{abstract}
The effects of Spirulina maxima supplementation on calcium, magnesium, iron, and zinc status were studied in a double-blind placebo-controlled trial of 50 obese subjects with treated hypertension, each randomized to receive $2 \mathrm{~g}$ of spirulina or a placebo daily for 3 months. At baseline and after treatment, the calcium, magnesium, iron, and zinc concentration in plasma was assessed. It was found that 3 months of $S$. maxima supplementation resulted in a significant decrease in the iron level in the plasma of obese patients. In conclusion, this is the first clinical study on the influence of spirulina supplementation on mineral status in obese patients with hypertension. Spirulina supplementation affects the iron status of obese Caucasians with well-treated hypertension.
\end{abstract}

Keywords Spirulina $\cdot$ Obesity $\cdot$ Treated hypertension . Minerals · Randomized trial

\section{Introduction}

Obesity is associated with an impairment of the body's mineral status. Multiple studies have indicated that obesity is

J. Suliburska

jsulibur@au.poznan.pl

1 Department of Human Nutrition and Hygiene, Poznan University of Life Sciences, Wojska Polskiego 31 Str., 60-624 Poznan, Poland

2 Department of Education and Obesity Treatment and Metabolic Disorders, University of Medical Sciences, Poznan, Poland

3 Orenburg State Medical University, Orenburg, Russia

4 All-Russian Research Institute of Medicinal and Aromatic Plants (VILAR), Moscow, Russia accompanied by altered iron homeostasis [1]. At the same time, weight reduction has been associated with improved iron metabolism [2]. It has been demonstrated that serum magnesium content decreases in experimental [3] and clinical studies $[4,5]$. Moreover, it has been proposed that magnesium deficiency in obese subjects may contribute to hypertension [6] and insulin resistance [5]. Recent data also indicate an association between inadequate calcium intake and increased body weight [7]. It has been also proposed that increased consumption of calcium in the diet may result in improvements in obesity and hypertension [8]. The mechanisms of antiobesity action of dietary calcium may involve decreased fat absorption, regulation of adipocyte proliferation, and apoptosis [9]. Finally, zinc concentration in both plasma and the erythrocytes of obese individuals was significantly lower than in lean individuals [10]. Experimental studies also provide additional data on the role of zinc deficiency in obesity pathogenesis in high-fat fed mice [11]. Taking into account the possible role of impaired zinc balance in hypertension [12], obesity-associated zinc deficiency may be an additional link between these two pathologies. It was found in another study that improvements in zinc status were associated with increases in insulin sensitivity in obese patients $[13,14]$.

Blue-green freshwater algae may be a good source of minerals for obese people, and especially of calcium and iron, due to their substantial levels $[15,16]$. Moreover, green algae show promising antiobesity properties. Spirulina is widely used in functional nutrition and medicine due to its antioxidant, anti-inflammatory, anticancer, and immunostimulatory activities [17]. At the same time, these microalgae are able to accumulate significant amounts of trace elements, thus serving as a supplemental nutritional source of essential elements [18]. Moreover, the metal-accumulating ability of spirulina is used in engineering to enrich it with certain trace elements [19]. 
The hypothesis in the present study is that oral supplementation with spirulina has an influence on mineral status in obese hypertensive patients receiving standard antihypertensive treatment. Patients were therefore randomized to receive $2 \mathrm{~g}$ of Spirulina maxima or a matching placebo daily, in order to measure the concentration of calcium, magnesium, iron, and zinc in plasma at baseline and after 3 months of treatment.

\section{Materials and Methods}

\section{Study Patients}

The study protocol was approved by the Research Ethics Committee of Poznań University of Medical Sciences, registered as case no. 599/12. Informed consent was obtained from all patients. The study was performed in accordance with the Declaration of Helsinki.

Among the 142 registered patients with hypertension and obesity screened in our outpatient clinic, a total of 50 (25 men, 25 women) were enrolled to the study.

The inclusion criteria were body mass index (BMI) equal to or greater than $30 \mathrm{~kg} / \mathrm{m}^{2}$, age 25 to 60 years, stable body weight $(<3 \mathrm{~kg}$ self-reported change during the previous 3 months), and well-controlled hypertension (meaning systolic blood pressure (SBP) less than $160 \mathrm{mmHg}$ and diastolic blood pressure (DBP) less than $100 \mathrm{mmHg}$ ) with stable treatment for at least 6 months.

The exclusion criteria were secondary obesity or secondary hypertension; diabetes; a history of coronary artery disease, stroke, congestive heart failure, or malignancy; a history of the use of any dietary supplements within the 3 months prior to the study; a current need for modification of antihypertensive therapy; abnormal liver or kidney function; any clinically significant process; a history of infection in the month prior to the study; nicotine or alcohol abuse; or other condition that, in the opinion of the investigators, would make participation not in the best interest of the patient or could prevent, limit, or confound the protocol-specified efficacy assessments.

\section{Study Design}

The study was designed as a randomized double-blind placebo-controlled trial with two parallel groups. Randomization was performed by an independent statistician. The participants were randomly assigned (in a 1:1 ratio) to receive with their morning meal for 3 months four capsules of either Hawaiian spirulina (Cyanotech Corporation, HI, USA) or a placebo. All supplements were packed in bottles without labeling. The Hawaiian spirulina capsules each contained $0.5 \mathrm{~g}$ of $S$. maxima
(60-70\% protein, gamma-linolenic acid (GLA), beta carotene, iron, and phycocyanin (PC)). The placebo consisted of pure microcrystalline cellulose. All patients were advised to continue their habitual diet and exercise patterns throughout the study. The intention-to-treat (ITT) population consisted of 50 patients.

\section{Anthropometric and Blood Pressure Measurements}

During the anthropometric measurements, the patients wore lightweight clothing and no shoes. Weight was measured to the nearest $0.1 \mathrm{~kg}$ and height to the nearest $0.1 \mathrm{~cm}$. Obesity was defined as a BMI of $30 \mathrm{~kg} / \mathrm{m}^{2}$ or greater (WHO, 1995). Blood pressure was measured seated, according to the guidelines of the European Society of Hypertension [20], using a digital electronic tensiometer (model 705IT, Omron Corporation, Kyoto, Japan). Hypertension was defined as the average of three measurements of arterial blood pressure obtained after 10 min of physical rest by the patients (twice at two different visits in the same month).

\section{Biochemical Measurements}

Blood samples were taken from each participant following an overnight fast and after lying in a supine position for $30 \mathrm{~min}$.

The levels of calcium, magnesium, iron, and zinc in plasma were determined by flame atomic absorption spectrometry (with a Zeiss AAS-3 spectrometer with deuterium background correction). In order to obtain the concentration of the plasma elements, the samples were diluted $(v / v 1: 1)$ as follows: for iron and zinc analyses, $0.01 \%$ Triton X-100 (Merck) was used, while for the calcium and magnesium analysis, aqueous solutions consisting of $0.01 \%$ Triton X-100 (Merck) and $0.05 \%$ lanthanum chloride (Merck) were used. The amounts of iron, zinc, calcium, and magnesium in the plasma samples were determined at the following respective wavelengths: $248.3,213.9,422.7$, and $285.2 \mathrm{~nm}$. The accuracy of the method was verified using a certified reference material (HUM ASY CONTROL 2, Randox) and was 95, 99, 94, and $99 \%$ for calcium, magnesium, iron, and zinc, respectively.

\section{Dietary and Supplement Intake}

Every 14 days, and also 3 days before the laboratory tests, dietary intake was assessed on the basis of dietary intake interviews (24-h recall). The level of nutrients in the daily diet was evaluated using a dietetics computer program (Dieta 5.0, 2011). The intake of nutrients and caffeine consumption during the study were constant and comparable between the groups. Physical activity was constant and unchanged in all subjects at the beginning of and after treatment. 
In this study, a single daily dosage of supplement was used in order to facilitate the patients taking it. During the interview with each patient on the first day of the study, the physician described taking the daily spirulina supplement and its benefits. Every 14 days, the patient visited the dietician to record the number of pills consumed over the previous 2-week period. During the first visit to the dietician, each patient received a diary in which to enter the time the supplement was taken each day. On subsequent visits, the diary was checked by either a dietician or a physician. The investigators maintained a $\log$ of all pills dispensed and returned. The drugs supplied to each subject were accounted for throughout the study. The level of compliance required was $90 \%$.

\section{Statistical Analysis}

It was calculated that a sample size of at least 20 patients in each group would yield at least an $80 \%$ chance of detecting a treatment effect as being statistically significant at the 0.05 alpha level. The results are given as mean values. Statistical calculations were performed using Statistica 10.0 software (StatSoft, Inc., Tulsa, OK, USA). The normality test was performed to assess normal distribution within the data. Statistical analysis was carried out using a factorial ANOVA. Mann-Whitney $U$ test was used to assess the differences between the groups at baseline. ITT analysis was performed. A $p$ value of less than 0.05 was regarded as significant.

\section{Results}

The baseline characteristics of both groups are shown in Table 1 . There were no statistically significant differences between the two treatment groups prior to the study. All subjects completed the study, and no significant changes in diets, physical activity, or antihypertensive treatment were recorded.

The amount of minerals in S. maxima is shown in Table 2.

The values of the concentration of the minerals in plasma in the spirulina and placebo groups, both before and after treatment, are summarized in Table 3, along with the $p$ values for the "treatment" and "time" factors and their interactions, as obtained from the ANOVA analysis. A statistically significant interaction between treatment and time factors (with both factors being statistically significant) was observed only for the iron level. The iron level was found to be significantly lower in the spirulina group than in the placebo group.

Following treatment, the concentration of calcium, magnesium, and zinc in plasma was not changed markedly in either of the groups.
Table 1 Baseline characteristics of Spirulina group and Placebo group (value are means $\pm \mathrm{SD}$ )

\begin{tabular}{llll}
\hline Analyzed parameters & $\begin{array}{l}\text { Spirulina group } \\
(n=25)\end{array}$ & $\begin{array}{l}\text { Placebo group } \\
(n=25)\end{array}$ & $P^{1}$ \\
\hline Male $(n)$ & 12 & 13 & \\
Female $(n)$ & 13 & 12 & NS \\
Age (year) & $49.3 \pm 8.7$ & $50.2 \pm 7.2$ & NS \\
Time since diagnosis of & $5.7 \pm 2.1$ & $5.6 \pm 2.5$ & \\
$\quad$ hypertension (year) & & & \\
Medication $(n)$ & 12 & 11 & \\
ACEI & 2 & 4 & NS \\
Sartan & 9 & 8 & NS \\
CCB & 4 & 3 & NS \\
B-bloker & 7 & 6 & NS \\
Diuretic & $33.5 \pm 6.7$ & $33.3 \pm 6.2$ & NS \\
BMI $\left(\mathrm{kg} / \mathrm{m}^{2}\right)$ & $148 \pm 15$ & $151 \pm 15$ & $\mathrm{NS}$ \\
SBP $(\mathrm{mmHg})$ & $84 \pm 9$ & $85 . \pm 9$ & $\mathrm{NS}$ \\
DBP $(\mathrm{mmHg})$ & $3.4 \pm 0.3$ & $3.3 \pm 0.2$ & \\
Ca $(\mathrm{mmol} / \mathrm{L})$ & $0.8 \pm 0.1$ & $0.8 \pm 0.1$ & $15.8 \pm 2.6$ \\
$\mathrm{Mg}(\mathrm{mmol} / \mathrm{L})$ & $16.6 \pm 3.8$ & $10.7 \pm 2.5$ & \\
Fe $(\mu \mathrm{mol} / \mathrm{L})$ & $10.0 \pm 3.5$ & & \\
Zn $(\mu \mathrm{mol} / \mathrm{L})$ & & & \\
\hline
\end{tabular}

$A C E I$ angiotensin-converting enzyme inhibitor, $C C B$ calcium channel blocker, $N S$ not statistically significant, $B M I$ body mass index, $S B P$ systolic blood pressure, $D B P$ diastolic blood pressure, $S D$ standard deviation

${ }^{1}$ Differences were tested using Mann-Whitney $U$ test

\section{Discussion}

The data indicate that spirulina consumption resulted in significantly decreased serum iron concentrations. Hypothetically, this effect may occur as a result of the iron-chelating activity of spirulina. In particular, it has been demonstrated that phycocyanin isolated from Spirulina platensis extract is capable of binding ferrous ions (from $\mathrm{FeSO}_{4}$ ) and ferric ions (from $\mathrm{FeCl}_{3}$ ) [21]. The presence of phycocyanin in other spirulina species, including the $S$. maxima [22] used in the current study, supports this hypothesis. Furthermore, it is known that blue-green algae bioaccumulate heavy metals and they

Table 2 Concentration of minerals in Hawaiian spirulina supplement

\begin{tabular}{lcc}
\hline Minerals & In 100 g of powder & $\begin{array}{l}\text { In } 2 \mathrm{~g} \text { (4 capsules) } \\
\text { of powder }\end{array}$ \\
\hline $\mathrm{Ca}(\mathrm{mg})$ & 583.3 & 11.7 \\
$\mathrm{Mg}(\mathrm{mg})$ & 746.7 & 14.9 \\
$\mathrm{Fe}(\mathrm{mg})$ & 175.3 & 3.5 \\
$\mathrm{Zn}(\mathrm{mg})$ & 57.3 & 1.2 \\
\hline
\end{tabular}


Table 3 Changes in mineral status during the supplementation in the spirulina and placebo groups

\begin{tabular}{|c|c|c|c|c|c|c|c|c|}
\hline \multirow[t]{2}{*}{ Analyzed parameters } & & \multicolumn{2}{|l|}{ Baseline } & \multicolumn{2}{|l|}{ After 3 months } & \multicolumn{3}{|l|}{ ANOVA } \\
\hline & & $\begin{array}{l}\text { Spirulina group } \\
(n=25)\end{array}$ & $\begin{array}{l}\text { Placebo group } \\
(n=25)\end{array}$ & $\begin{array}{l}\text { Spirulina group } \\
(n=25)\end{array}$ & $\begin{array}{l}\text { Placebo group } \\
(n=25)\end{array}$ & $\begin{array}{l}\text { Treatment } \\
P \text { value }\end{array}$ & Time & Interaction \\
\hline \multicolumn{9}{|c|}{ Intention-to-treat population, $n=50$} \\
\hline $\mathrm{Ca}(\mathrm{mmo} / \mathrm{L})$ & $\begin{array}{l}\text { Mean } \pm \text { SD } \\
\text { Median }\end{array}$ & $\begin{array}{l}3.41 \pm 0.27 \\
3.43\end{array}$ & $\begin{array}{l}3.25 \pm 0.20 \\
3.27\end{array}$ & $\begin{array}{l}3.55 \pm 0.32 \\
3.53\end{array}$ & $\begin{array}{l}3.31 \pm 0.33 \\
3.29\end{array}$ & 0.202 & 0.106 & 0.122 \\
\hline $\mathrm{Mg}(\mathrm{mmol} / \mathrm{L})$ & $\begin{array}{l}\text { Mean } \pm \text { SD } \\
\text { Median }\end{array}$ & $\begin{array}{l}0.75 \pm 0.07 \\
0.74\end{array}$ & $\begin{array}{l}0.80 \pm 0.11 \\
0.78\end{array}$ & $\begin{array}{l}0.75 \pm 0.10 \\
0.75\end{array}$ & $\begin{array}{l}0.78 \pm 0.09 \\
0.79\end{array}$ & 0.288 & 0.203 & 0.102 \\
\hline $\mathrm{Fe}(\mu \mathrm{mol} / \mathrm{L})$ & $\begin{array}{l}\text { Mean } \pm \text { SD } \\
\text { Median }\end{array}$ & $\begin{array}{l}16.63 \pm 3.75 \\
16.58\end{array}$ & $\begin{array}{l}15.84 \pm 2.55 \\
15.90\end{array}$ & $\begin{array}{l}12.98 \pm 2.75 \\
13.75\end{array}$ & $\begin{array}{l}16.11 \pm 3.12 \\
15.98\end{array}$ & 0.008 & 0.008 & 0.001 \\
\hline $\mathrm{Zn}(\mu \mathrm{mol} / \mathrm{L})$ & $\begin{array}{l}\text { Mean } \pm \text { SD } \\
\text { Median }\end{array}$ & $\begin{array}{l}10.03 \pm 3.54 \\
9.09\end{array}$ & $\begin{array}{l}10.71 \pm 2.50 \\
9.30\end{array}$ & $\begin{array}{l}9.78 \pm 2.14 \\
9.36\end{array}$ & $\begin{array}{l}10.92 \pm 1.81 \\
9.38\end{array}$ & 0.517 & 0.105 & 0.418 \\
\hline
\end{tabular}

Data are arithmetic mean \pm SD

$S D$ standard deviation, NS not significant

Italic values indicate ANOVA test, significant differences at $P<.05$

act as bioadsorbents for them [23, 24]. Therefore, spirulina may decrease absorption of iron from food. Moreover, lower bioavailability of iron may be partly caused by interaction between heavy metals in spirulina and iron, because as it is known, e.g., cadmium inhibits iron absorption.

There is a growing body of data on the influence of spirulina on metabolic syndrome and its components. In particular, consumption of spirulina in a mouse model of metabolic syndrome based on monosodium glutamate injection resulted in decreased serum lipids and leptin concentrations. Moreover, spirulina has been shown to reduce liver and adipose tissue inflammation, and even more effective than pioglitazone [25]. Similar results have been observed in a recent study [26]. The earlier study also demonstrated a protective effect of spirulina against fructose-induced fatty liver formation [27]. Existing clinical studies conform to the experimental data. It has been shown that the intake of $2.8 \mathrm{~g}$ of spirulina thrice a day results in a significant reduction in body weight [28]. A report on three cases of nonalcoholic fatty liver disease indicated the efficacy of $S$. maxima consumption in improving metabolic and ultrasonographic parameters [29]. $S$. maxima is also considered a potential antiobesity drug [30]. Taking into account the role of oxidative stress and inflammation in the pathogenesis of obesity and metabolic syndrome, the antioxidant and anti-inflammatory properties of spirulina [31] may mediate the observed protective effect.

A number of studies have highlighted the role of impaired iron homeostasis in metabolic syndrome [32] and its components, such as obesity [33] and nonalcoholic fatty liver disease [34]. Moreover, iron chelation has been shown to be efficient in the prevention of adipocyte hypertrophy, oxidative stress, and inflammation [35]. In previous studies, a deficit of iron in western diet, high in fat and sugar, improves lipid and carbohydrate metabolism [36]. In clinical trial, it was found that phlebotomy, with consecutive reduction of body iron stores, lowered blood pressure and resulted in improvements in markers of cardiovascular risk and glycemic control in patients with metabolic syndrome [37]. It is claimed that iron depletion upregulates glucose uptake and increases insulin receptor activity in hepatocytes and that the main mechanisms responsible for improving carbohydrate metabolism are associated with the inhibition of oxidative stress [36]. In the light of the recent finding, it may be supposed that the observed protective effect of spirulina in metabolic syndrome and obesity may be mediated by the improvement of iron homeostasis and the prevention of iron overload.

Unquestionably, this study has some limitations: the study group is rather small and only selected minerals were determined. In addition, the minerals were measured only in serum and the concentrations of mineral in erythrocytes or urine were not assessed. Moreover, the association between mineral status and body mass, blood pressure, and other biochemical parameters was not determined. The evaluation of these relationships would allow a wider discussion on the impact of spirulina treatment on the mineral status in obesity and hypertension.

In conclusion, treatment with $S$. maxima resulted in decreased serum iron levels in hypertensive obese adults. 
However, further in vivo and in vitro studies are required to estimate the exact mechanisms of the influence of spirulina consumption on iron homeostasis in obesity.

Acknowledgments This research was partly supported by a grant from the National Science Center, Poland (2669/B/P01/2011/40).

\section{Compliance with Ethical Standards}

Conflict of Interest The authors declare that they have no competing interests.

Open Access This article is distributed under the terms of the Creative Commons Attribution 4.0 International License (http:// creativecommons.org/licenses/by/4.0/), which permits unrestricted use, distribution, and reproduction in any medium, provided you give appropriate credit to the original author(s) and the source, provide a link to the Creative Commons license, and indicate if changes were made.

\section{References}

1. Becker C, OrozcoM SNW, Schümann K (2015) Iron metabolism in obesity: how interaction between homoeostatic mechanisms can interfere with their original purpose. Part I: underlying homoeostatic mechanisms of energy storage and iron metabolisms and their interaction. J Trace Elem Med Biol 30:195-201

2. Gong L, Yuan F, Teng J, Li X, Zheng S, Lin L, Deng H, Ma G, Sun C, Li Y (2014) Weight loss, inflammatory markers, and improvements of iron status in overweight and obese children. J Pediatr 164 (4):795-800

3. Ewis S, Abdel-Rahman M (1995) Effects of metformin on glutathione and magnesium in normal and streptozotocin-induced diabetic rats. J Appl Toxicol 15:387-390

4. Rodríguez-Morán M, Guerrero-Romero F (2004) Elevated concentrations of TNF-alpha are related to low serum magnesium levels in obese subjects. Magnes Res 17(3):189-196

5. Huerta MG, Roemmich JN, Kington ML, Bovbjerg VE, Weltman AL, Holmes VF, Patrie JT, Rogol AD, Nadler JL (2005) Magnesium deficiency is associated with insulin resistance in obese children. Diabetes Care 28(5):1175-1181

6. Nielsen FH (2010) Magnesium, inflammation, and obesity in chronic disease. Nutr Rev 68(6):333-340

7. Villarroel P, Villalobos E, Reyes M, Cifuentes M (2014) Calcium, obesity, and the role of the calcium-sensing receptor. Nutr Rev 72 (10):627-637

8. Zemel MB (2001) Calcium modulation of hypertension and obesity: mechanisms and implications. J Am Coll Nutr 20(5 Suppl): $428 \mathrm{~S}-435 \mathrm{~S}$

9. Song Q, Sergeev IN (2012) Calcium and vitamin D in obesity. Nutr Res Rev 25(01):130-141

10. Marreiro DDN, Fisberg M, Cozzolino SMF (2002) Zinc nutritional status in obese children and adolescents. Biol Trace Element Res 86 (2):107-122

11. Liu MJ, Bao S, Bolin ER, Burris DL, Xu X, Sun Q, Killilea DW, Shen Q, Ziouzenkova O, Belury MA, Failla ML, Knoell DL (2013) Zinc deficiency augments leptin production and exacerbates macrophage infiltration into adipose tissue in mice fed a high-fat diet. J Nutr 143(7):1036-1045

12. Tubek S (2007) Role of zinc in regulation of arterial blood pressure and in the etiopathogenesis of arterial hypertension. Biol Trace Elem Res 117(1-3):39-51
13. Suliburska J, Bogdański P, Szulińska M, Pupek-Musialik D, Jabłecka A (2014) Changes in mineral status are associated with improvements in insulin sensitivity in obese patients following Larginine supplementation. Eur J Nutr 53:387-393

14. Suliburska J, Bogdanski P, Szulinska M, Stepien M, PupekMusialik D, Jablecka A (2012) Effects of green tea supplementation on elements, total antioxidants, lipids, and glucose values in the serum of obese patients. Biol Trace Elem Res 149(3):315-322

15. Gutiérrez-Salmeán G, Fabila-Castillo L, Chamorro-Cevallos G (2015) Nutritional and toxicological aspects of Spirulina (Arthrospira). Nutr Hosp 32(1):34-40

16. Khan Z, Bhadouria P, Bisen PS (2005) Nutritional and therapeutic potential of spirulina. Curr Pharm Biotechnol 6(5):373-379

17. Hoseini SM, Khosravi-Darani K, Mozafari MR (2013) Nutritional and medical applications of spirulina microalgae. Mini Rev Med Chem 13(8):1231-1237

18. Molnár S, Kiss A, Virág D, Forgó P (2013) Comparative studies on accumulation of selected microelements by Spirulina platensis and Chlorella vulgaris with the prospects of functional food development. J Chem Eng Process Technol 4:7

19. Dmytryk A, Saeid A, Chojnacka K (2014) Biosorption of microelements by spirulina: towards technology of mineral feed supplements. Sci World J 2014:356328. doi:10.1155/2014/356328

20. ESH/ESC Task Force for the Management of Arterial Hypertension (2013) Practice guidelines for the management of arterial hypertension of the European Society of Hypertension (ESH) and the European Society of Cardiology (ESC): ESH/ESC Task Force for the Management of Arterial Hypertension. J Hypertens 10:19251938

21. Bermejo P, Piñero E, Villar AM (2008) Iron-chelating ability and antioxidant properties of phycocyanin isolated from a protean extract of Spirulina platensis. Food Chem 110(2):436-445

22. Yu P, Li JR, Cen PL (2002) Cloning and sequencing of the phycocyanin gene from spirulina maxima and its evolutionary analysis. $\mathrm{J}$ Appl Phycol 14(4):307-310

23. Siva Kiran RR, Madhu GM, Satyanarayana SV, Bindiya P (2013) Bioaccumulation of cadmium in blue green algae Spirulina (Arthrospira) Indica. J Bioremed Biodegrad 20:383-388

24. Balaji S, Kalaivani T, Rajasekaran C, Shalini M, Siva R, Singh RK, Akthar MA (2014) Arthrospira (Spirulina) species as bioadsorbents for lead, chromium, and cadmium - a comparative study. Clean Soil, Air, Water 42(12):1790-1797

25. Fujimoto M, Tsuneyama K, Fujimoto T, Selmi C, Gershwin ME, Shimada Y (2012) Spirulina improves non-alcoholic steatohepatitis, visceral fat macrophage aggregation, and serum leptin in a mouse model of metabolic syndrome. Dig Liver Dis 44(9): 767-774

26. Madhavadas S, Subramanian S (2015) Combination of Spirulina with glycyrrhizin prevents cognitive dysfunction in aged obese rats. J Pharmacol 47(1):39-44

27. González DRC, Miranda-Zamora R, Diaz-Zagoya JC, JuárezOropeza MA (1992) Preventive effect of Spirulina maxima on the fatty liver induced by a fructose-rich diet in the rat, a preliminary report. Life Sci 53(1):57-61

28. Becker EW, Jakober B, Luft D, Schmulling RM (1987) Clinical and biochemical evaluations of the alga Spirulina with regard to its application in the treatment of obesity. A double-blind cross-over study. Nutrition Reports International (USA) 33: 4.

29. Ferreira-Hermosillo A, Torres-Duran PV, Juarez-Oropeza MA (2010) Hepatoprotective effects of Spirulina maxima in patients with non-alcoholic fatty liver disease: a case series. J Med Case Rep 4(1): 103

30. Araldi RP, Rechiutti BM, Mendes TB, Ito ET, Souza EB (2014) Mutagenic potential of Cordia ecalyculata alone and in association with Spirulina maxima for their evaluation as candidate anti-obesity drugs. Genet Mol Res 7,13(3): 5207-5220 
31. Deng R, Chow TJ (2010) Hypolipidemic, antioxidant, and antiinflammatory activities of microalgae Spirulina. Cardiovas Therap 28(4):e33-e45

32. Bozzini C, Girelli D, Olivieri O, Martinelli N, Bassi A, De Matteis G, Tenuti I, Lotto V, Friso S, Pizzolo F, Corrocher RR (2005) Prevalence of body iron excess in the metabolic syndrome. Diabetes Care 28(8):2061-2063

33. Nikonorov AA, Skalnaya MG, Tinkov AA, Skalny AV (2015) Mutual interaction between iron homeostasis and obesity pathogenesis. J Trace Elem Med Biol 30:207-214

34. Dongiovanni P, Fracanzani AL, Fargion S, Valenti L (2011) Iron in fatty liver and in the metabolic syndrome: a promising therapeutic target. J Hepatol 55(4):920-932
35. Tajima S, Ikeda Y, Sawada K, Yamano N, Horinouchi Y, Kihira Y, Ishizawa K, Izawa-Ishizawa Y, Kawazoe K, Tomita S, Minakuchi K, Tsuchiya K, Tamaki T (2012) Iron reduction by deferoxamine leads to amelioration of adiposity via the regulation of oxidative stress and inflammation in obese and type 2 diabetes KKAy mice. Am J Physiol Endocrinol Metab 302(1):E77-E86

36. Suliburska J (2014) The impact of iron content in a diet high in fat, fructose, and salt on metabolic state and mineral status of rats. J Physiol Biochem 70(1):27-32

37. Houschyar KS, Lüdtke R, Dobos GJ, Kalus U, Broecker-Preuss M, Rampp T, Brinkhaus B, Michalsen A (2012) Effects of phlebotomy-induced reduction of body iron stores on metabolic syndrome: results from a randomized clinical trial. BMC Med 10: 54 